\title{
PENERAPAN METODE DOUBLE EXPONENTIAL SMOOTHING UNTUK PERAMALAN TINGKAT INDEKS PEMBANGUNAN MANUSIA BERBASIS SISTEM INFORMASI GEOGRAFIS DI PROVINSI JAWA TENGAH
}

\author{
Roni Yoga Irawan"), Wawan Laksito' ${ }^{2)}$, Setiyowati ${ }^{3)}$ \\ 1) Program Studi Sistem Informasi, STMIK Sinar Nusantara Surakarta \\ 2) Program Studi Teknik Informatika, STMIK Sinar Nusantara Surakarta \\ 3) Program Studi Manajemen Informatika, STMIK Sinar Nusantara Surakarta \\ 1) roni.yoga08@gmail.com; ${ }^{2)}$ wlaksito@sinus.ac.id; ${ }^{3)}$ setiyowati@sinus.ac.id
}

\begin{abstract}
The basic goal in quality human development is to overcome problems in society are poverty, unemployment, illiteracy, food security and democracy enforcement. But in its achievements there are several aspects of development that failed. To measure the success of a region's performance in the field of human development can be done by calculating the Human Development Index. The Human Development Index is an index that includes three indicators, which are health indicators, education level, and economic indicators. The Province of Central Java is divided into 29 districts and 6 cities, so it has a varied picture of development. The application forecasting the Human Development Index indicator is created using the PHP programming language and the MySQL Server database. Application of Human Development Index forecasting produces forecasting calculations with the value $\alpha=0.9$ produces forecasting the following year: 69.3612 with the smallest MSE error: 0.1578 and MAPE value: 0.4894 . This study produces accurate forecasting because of low error values.
\end{abstract}

Keywords: Forecasting, Exponential Smoothing, Double Exponential Smoothing, Human Development Index, Geographic Information Systems.

\section{PENDAHULUAN}

Tujuan dalam pembangun bangsa adalah manusia yang berkualitas. Keberhasilan pembangunan bangsa diukur dari beberapa aspek salah satunya adalah aspek pembangunan manusia. Untuk mengukur tingkat keberhasilan suatu wilayah dalam bidang pembangunan manusia dapat dilakukan dengan menghitung Indeks Pembangunan Manusia (IPM).

IPM merupakan suatu indeks yang mencakup tiga indikator yaitu indikator kesehatan, tingkat pendidikan, dan indikator ekonomi. Untuk menghitung IPM tersebut, sumber data yang digunakan dari Sensus Penduduk, Proyeksi Penduduk dan Survei Sosial Ekonomi. Namun saat ini, belum adanya suatu media informasi yang dapat menyediakan informasi mengenai peramalan indeks pembangunan manusia berbasis internet.

Peramalan dapat dilakukan dengan mengambil data masa lalu untuk mendapatkan hasil di masa depan dengan metode tertentu. Ada tiga model yang dikenal untuk menganalisis peramalan, yaitu model ekonometrika, model deret berkala (time series) dan model ramalan kualitatif. Model ramalan Exponential Smoothing merupakan salah satu model ramalan deret berkala. Teknik peramalan dengan metode exponential smoothing dilakukan dengan perhitungan secara terus menerus menggunakan data baru, untuk meramalkan kemungkinan pada periode mendatang.

Berdasarkan uraian di atas, penelitian ini membuat aplikasi peramalan tingkat indeks pembangunan dengan metode peramalan dengan Exponential Smoothing yang berbasis sistem informasi geografis.

\section{TINJAUAN PUSTAKA}

\subsection{Penelitian Terkait}

Penelitian [1] terkait yang membahas peramalan tingkat indeks pembangunan manusia di Provinsi Jawa Tengah dengan metode Exponential Smoothing, dalam penelitian tersebut menyajikan data dan peramalan indeks pembangunan manusia 
dalam bentuk aplikasi yang berbasis Microsoft Visual Basic 6.0 yang ada di Provinsi Jawa Tengah.

Kemudian penelitian [2] tentang peramalan produksi daging yang berbasis sistem informasi geografis di Provinsi Gorontalo. Dalam penelitiannya di kembangkan aplikasi peramalan dan pemetaan dengan metode Double Exponential Smoothing yang berbasis web Sistem Informasi Geografis.

Selanjutnya pada penelitian [3] dilakukan prediksi harga sembako menggunakan metode Double Exponential Smoothing (DES) Di Kota Surakarta. Hasil penelitian tersebut adalah aplikasi prediksi sembako berbasis Visual Basic. Penelitian selanjutnya [4] melakukan perhitungan peramalan permintaan pasar di China terhadap penjualan kendaraan listrik dari Amerika. Peneliti mengambil data sampel penjualan terdahulu untuk dilakukan peramalan, selain itu juga memperhitungkan faktor-faktor yang mempengaruhi, metode peramalan yang digunakan adalah Exponential Smoothing.

\subsection{Pembangunan Manusia}

Pembangunan manusia adalah suatu proses untuk memperbanyak pilihan-pilihan yang dimiliki oleh manusia [5]. Indeks Pembangunan Manusia (IPM) dibentuk oleh 3 (tiga) dimensi dasar:

a. Umur panjang dan hidup sehat (a long and healthy life)

b. Pengetahuan (knowledge)

c. Standar hidup layak (decent standard of living)

Rumus perhitungan indeks pembangunan manusia dijelaskan pada rumus (1).

$I P M=\sqrt[3]{\text { I kesehatan } \times \text { I pendidikan } \times \text { I pengeluaran }} \times 10$

1. Indikator kesehatan diukur harapan hidup saat lahir (tingkat kematian bayi).

Rumus (2) digunakan untuk menghitung indikator kesehatan.

$I$ kesehatan $=\frac{A H H-A H H_{\min }}{A H H_{\text {maks }}-A H H_{\text {min }}}$

2. Tingkat pendidikan diukur dengan lamanya pendidikan seorang penduduk. Untuk menghitung indikator pendidikan menggunakan rumus (3), (4), dan (5).
I $H L S=\frac{H L S-H L S_{\min }}{H L S_{\text {maks }}-H L S_{\min }}$

$I R L S=\frac{R L S-R L S_{\min }}{R L S_{\text {maks }}-R L S_{\text {min }}}$

I pendidikan $=\frac{I H L S+I R L S}{2}$

3. Standar kehidupan diukur dengan tingkat pengeluaran per kapita per tahun yang telah di sesuaikan. Rumus (6) digunakan untuk menghitung indikator standar kehidupan.

$I$ pengeluaran $=\frac{I n(\text { pengeluaran })-I n\left(\text { pengeluaran }_{\min }\right)}{I n\left(\text { pengeluaran } n_{\text {maks }}\right)-I n\left(\text { pengeluaran }_{\min }\right)}$

\subsection{Peramalan}

Peramalan (forecasting) didefinisikan sebagai alat/teknik untuk memprediksi atau memperkirakan suatu nilai pada masa yang akan datang dengan memperhatikan suatu nilai pada masa yang akan datang dengan memperhatikan data atau informasi yang relevan, baik data/informasi masa lalu maupun data/informasi saat ini [6].

1. Metode Serial Waktu

Metode serial waktu adalah metode yang digunakan untuk menganalisa serangkaian data yang merupakan fungsi dari waktu. Pola dari serangkaian data dalam serial waktu dapat dikelompokkan kedalam pola dasar yang ditunjukkan pada Gambar 1.

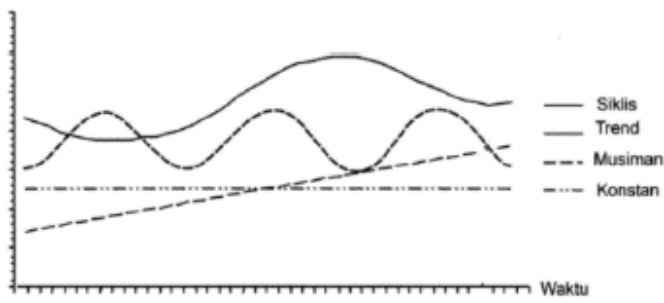

Gambar 1. Pola Dasar Serial Waktu

2. Pemulusan Eksponensial

Pemulusan eksponensial (exponential smoothing) adalah metode peramalan yang didasarkan pada pemakaian rata-rata bergerak, namun ini lebih merupakan rata-rata bergerak yang dibobot dan bukan seperti sebelumnya di mana semua nilai data sebelumnya sama bobotnya [7].

a. Pemulusan Eksponensial Tunggal

Pada metode ini digunakan jika data tidak mempengaruhi secara signifikan oleh faktor 
trend dan musiman. Setiap data diberi bobot tertentu dengan data yang lebih baru diberi bobot yang lebih besar dari pada data yang lebih lama [8]. Persamaan metode Pemulusan eksponensial Tunggal adalah sebagai berikut:

$F_{t+1}=\alpha X_{t}+(1-\alpha) F_{t}$

\section{b. Double Exponential Smoothing}

Metode Double Exponential Smoothing ini biasanya lebih tepat digunakan untuk meramalkan data yang mengalami trend kenaikan. Proses perhitungan smoothing dilakukan dua kali. Persamaan metode Double Exponential Smoothing adalah sebagai berikut:

$S^{\prime}{ }_{t}=\alpha X_{t}+(1-\alpha) S_{t-1}^{\prime}$

$S^{\prime \prime}{ }_{t}=\alpha S^{\prime}{ }_{t}+(1-\alpha) S^{\prime \prime}{ }_{t-1}$

$\alpha_{t}=S^{\prime}{ }_{t}+\left({S^{\prime}}_{t}-S^{\prime \prime}{ }_{t}\right)=2 S^{\prime}{ }_{t}-S^{\prime \prime}{ }_{t}$

$b_{t}=\frac{\alpha}{1-\alpha}\left(S^{\prime}{ }_{t}-S^{\prime \prime}{ }_{t}\right)$

$F_{t+m}=\alpha+b_{t} m$

c. Pemulusan Eksponensial Triple Metode ini adalah metode yang dikemukakan oleh Brown, seperti pemulusan eksponensial linier yang digunakan untuk meramalkan data dengan pola trend dasar, bentuk pemulusan yang lebih tinggi digunakan bila pola data adalah kuadratik, kubik, atau orde yang lebih tinggi. Untuk pemulusan kuadratik, pendekatan dasar adalah memasukkan tingkat pemulusan tambahan (pemulusan triple) dan memberlakukan persamaan peramalan kuadratik [9].

Persamaan metode Pemulusan Eksponensial Triple adalah sebagai berikut:

$$
\begin{aligned}
& S^{\prime \prime \prime}{ }_{t}=\alpha S^{\prime \prime}{ }_{t}+(1-\alpha) S^{\prime \prime \prime}{ }_{t-1} \\
& a_{t}=3 S^{\prime}{ }_{t}-3 S^{\prime \prime} t+S^{\prime \prime \prime}{ }_{t} \\
& b_{t}=\frac{\alpha^{2}}{2(1-\alpha)^{2}}\left[(6-5 \alpha) S^{\prime}{ }_{t}-(10-8 \alpha) S^{\prime \prime}{ }_{t}+(4-3 \alpha) S^{\prime \prime \prime}{ }_{t}\right]
\end{aligned}
$$

\section{Ketepatan Ramalan}

Pengukuran nilai ketepatan peramalan memerlukan nilai selisih antara data dengan peramalan yakni melihat nilai Mean Square Error (MSE) atau Mean Absolute Error (MAE) yang kecil.

a. Mean Square Error (MSE)

Mean Square Error (MSE) adalah kuadrat ratarata nilai error kuadrat dari kesalahan meramal.
$M S E=\frac{\sum\left|x_{t}-S_{t}\right|^{2}}{n}$

b. Mean Absolute Percentage Error (MAPE)

Mean Absolute Percentage Error (MAPE) adalah persentase rata-rata nilai absolute dari kesalahan meramal (tidak dihiraukan tanda positif atau negatifnya).

$M A P E=\frac{\sum\left|x_{t}-S_{t}\right|}{x_{t}} \times \frac{100 \%}{n}$

\subsection{PHP (Hypertext Preprosesor)}

PHP (PHP: Hypertext Preprosesor) adalah suatu bahasa pemrograman yang digunakan untuk menerjemahkan baris kode program menjadi kode mesin yang dapat dimengerti oleh komputer yang bersifat server-side yang dapat ditambahkan ke dalam HTML [10].

\subsection{Google Maps}

Google Maps adalah suatu peta dunia untuk melihat suatu daerah menggunakan browser. Google Maps memilki fitur yang ditambahkan dalam web dengan Google Maps API. Google Maps API adalah suatu library yang berbentuk JavaScript [11].

\subsection{Keyhole Markup Language (KML)}

Keyhole Markup Language (KML) adalah sebuah $X M L$ berbasis bahasa geografis skema untuk mengungkapkan penjelasan dan visualisasi yang ada, peta dua dimensi dan tiga dimensi Bumi browser [12].

\section{METODE PENELITIAN}

\subsection{Sumber Data}

Sumber data yang digunakan dalam penelitian adalah data sekunder. Data yang diperoleh dari Web Site Badan Pusat Statistik dan Badan Pusat Statistik Kota Surakarta yang terdiri dari data Angka Harapan Hidup, Harapan Lama Sekolah, Rata-rata Lama Sekolah, data Pengeluaran Per kapita Per Tahun yang telah di sesuaikan yang diambil dari sensus penduduk, proyeksi penduduk dan Survei Sosial Ekonomi. Selain itu juga data Indeks Pembangunan Manusia khusus nya di Jawa Tengah. Sumber data yang digunakan dari data sekunder Sensus Penduduk, Proyeksi Penduduk dan Survei Sosial Ekonomi.

Selain data BPS, juga data teknik perhitungan metode Exponential Smoothing untuk peramalan dan teknik perancangan aplikasi yang di peroleh dari studi pustaka. 


\subsection{Metode Analisa Data}

Metode untuk menganalisa pola umum data menggunakan grafik. Dengan melihat grafik dari data tiap indikator Indeks Pembangunan Manusia dari tahun 2010 sampai tahun 2016 sudah dapat melihat pola datanya.

Peramalan dilakukan untuk tiap indikator IPM, dimana hasil peramalan tersebut digunakan untuk menghitung IPM di tahun yang diramalkan, peramalan menggunakan metode Exponential Smoothing.

\subsection{Metode Analisa dan Desain Sistem}

\section{Analisa Sistem}

Peramalan Indeks Pembangunan Manusia dihitung dengan nilai peramalan dari tiap indikator Indeks Pembangunan Manusia yang terdiri dari indeks kesehatan, indeks pendidikan dan indeks pengeluaran. Selanjutnya dilakukan perhitungan IPM peramalan dengan menggunakan data hasil peramalan indikator.

\section{Desain sistem}

Desain sistem yaitu membuat perancangan menggunakan UML yang sesuai dengan hasil analisa sistem.

\subsection{Analisa Kebutuhan Sistem}

\section{Analisa kebutuhan perangkat keras}

Merupakan sebuah sistem komputer secara fisik yang terdiri dari komponen-komponen yang saling terkait dari masukkan, proses, dan keluaran.

2. Analisa kebutuhan perangkat lunak

Perangkat lunak yang digunakan untuk membuat dan mengoperasikan aplikasi adalah Google API, Google Fusion, Bootstrap, Chart JS dan MySQL Server.

\subsection{Perancangan Sistem}

Perancangan sistem menggunakan perancangan berbasis objek dengan analisa Unified Modeling Language (UML). UML menyediakan notasi-notasi yang membantu memodelkan sistem dari berbagai perspektif.

1. Diagram Use Case

Diagram Use Case menggambarkan apa saja aktivitas yang dilakukan oleh suatu sistem dari sudut pandang pengamatan luar.

2. Diagram Aktivitas

Diagram ini berfokus pada objek yang dalam suatu proses (atau proses menjadi suatu objek), diagram aktivitas berfokus pada aktivitasaktivitas yang terjadi yang terkait dalam suatu proses tunggal.

\section{Diagram Sekuen}

Diagram Sekuen merupakan salah satu diagram interaksi yang menjelaskan bagaimana suatu operasi itu dilakukan. Diagram ini diatur berdasarkan waktu.

4. Diagram Kelas

Diagram kelas memberikan pandangan secara luas dari suatu sistem dengan menunjukkan kelas-kelasnya dan hubungan mereka.

\subsection{Pembuatan Sistem}

Pembuatan sistem ini menggunakan aplikasi Bootstrap dan Dreamweaver 1 serta Bahasa pemrograman PHP, sedangkan database menggunakan MySQL. Dalam mengintegrasikan data dengan peta menggunakan Google API dan Google Fusion.

\subsection{Pengujian}

1. Black Box Testing

Pengujian terfokus pada apakah unit program memenuhi kebutuhan (requirement) yang disebutkan dalam spesifikasi.

2. Validitas Data

Pengujian validitas data dilakukan untuk membandingkan hasil perhitungan peramalan, dengan perhitungan Indeks Pembangunan Manusia dari Badan Pusat Statistik. Pengujian dengan menggunakan Mean Absolute Error (MAE) dan Mean Square Error (MSE).

\section{HASIL DAN PEMBAHASAN}

4.1. Contoh Kasus

Dalam kasus ini, digunakan data sampel dari angka harapan hidup, rata-rata lama sekolah, harapan lama sekolah dan PNB di Kabupaten Cilacap dari tahun 2010 hingga 2016, seperti pada Tabel 1. Untuk data PNB dikonversikan dengan Logaritma Natural (LN), menurut BPS Kota Surakarta, konversi dilakukan agar sama dengan satuan data indikator lainnya.

Tabel 1 Data di Kabupaten Cilacap

\begin{tabular}{|c|c|c|c|c|}
\hline Tahun & AHHP & RLS & HLS & PNB (LN) \\
\hline 2010 & 72,45 & 6,26 & 10,56 & 15,95796 \\
\hline 2011 & 72,55 & 6,27 & 10,71 & 15,99036 \\
\hline 2012 & 72,65 & 6,28 & 11,34 & 16,0093 \\
\hline 2013 & 72,75 & 6,43 & 11,98 & 16,02055 \\
\hline 2014 & 72,8 & 6,48 & 12,27 & 16,0228 \\
\hline 2015 & 73 & 6,58 & 12,28 & 16,05099 \\
\hline 2016 & 73,11 & 6,9 & 12,29 & 16,08527 \\
\hline
\end{tabular}

Berdasarkan Tabel 1 akan dicari nilai indikator pendidikan, indikator kesehatan dan indikator ekonomi. 


\section{a. Indikator Kesehatan}

1. Tahun 2010

I kesehatan $=(72,45-20) /(85-20)=0,8069$

2. Tahun 2011

I kesehatan $=(72,55-20) /(85-20)=0,8085$

3. Tahun 2012

I kesehatan $=(72,65-20) /(85-20)=0,81$

4. Tahun 2013

I kesehatan $=(72,75-20) /(85-20)=0,8115$

5. Tahun 2014

I kesehatan $=(72,55-20) /(85-20)=0,8123$

6. Tahun 2015

I kesehatan $=(72,8-20) /(85-20)=0,8154$

7. Tahun 2016

I kesehatan $=(73,11-20) /(85-20)=0,8171$

b. Indikator RLS

1. Tahun 2010

I RLS $=(6,26-0) /(0-15)=0,417$

2. Tahun 2011

I RLS $=(6,27-0) /(0-15)=0,418$

3. Tahun 2012

I RLS $=(6,28-0) /(0-15)=0,419$

4. Tahun 2013

I RLS $=(6,43-0) /(0-15)=0,429$

5. Tahun 2014

I RLS $=(6,48-0) /(0-15)=0,432$

6. Tahun 2015

I RLS $=(6,58-0) /(0-15)=0,439$

7. Tahun 2016

I RLS $=(6,9-0) /(0-15)=0,46$

c. Indikator HLS

1. Tahun 2010

I HLS $=(10,56-0) /(0-18)=0,587$

2. Tahun 2011

I HLS $=(10,71-0) /(0-18)=0,595$

3. Tahun 2012

I HLS $=(11,34-0) /(0-18)=0,630$

4. Tahun 2013

I HLS $=(11,98-0) /(0-18)=0,666$

5. Tahun 2014

I HLS $=(12,27-0) /(0-18)=0,682$

6. Tahun 2015

I HLS $=(12,28-0) /(0-18)=0,682$

7. Tahun 2016

I HLS $=(12,29-0) /(0-18)=0,683$

d. Indikator Pendidikan

1. Tahun 2010

I pendidikan $=(0,587+0,417) / 2=0,502$

2. Tahun 2011

I pendidikan $=(0,595+0,418) / 2=0,507$

3. Tahun 2012

I pendidikan $=(0,630+0,419) / 2=0,524$

4. Tahun 2013

I pendidikan $=(0,666+0,429) / 2=0,547$
5. Tahun 2014

I pendidikan $=(0,682+0,432) / 2=0,557$

6. Tahun 2015

I pendidikan $=(0,682+0,439) / 2=0,560$

7. Tahun 2016

I pendidikan $=(0,683+0,46) / 2=0,571$

e. Indikator Ekonomi

1. Tahun 2010

I pengeluaran $=(15,95796-13,8229) /(17,0954-$ $13,8229)=0,6524$

2. Tahun 2011

I pengeluaran $=(15,99036-13,8229) /(17,0954-$ $13,8229)=0,6625$

3. Tahun 2012

I pengeluaran $=(16,0093-13,8229) /(17,0954-$ $13,8229)=0,6683$

4. Tahun 2013

I pengeluaran $=(16,02055-13,8229) /(17,0954-$ $13,8229)=0,6717$

5. Tahun 2014

I pengeluaran $=(16,0228-13,8229) /(17,0954-$

$13,8229)=0,6724$

6. Tahun 2015

I pengeluaran $=(16,05099-13,8229) /(17,0954-$ $13,8229)=0,681$

7. Tahun 2016

I pengeluaran $=(16,08527-13,8229) /(17,0954-$ $13,8229)=0,6915$

Hasil perhitungan diatas ditunjukkan di Tabel 2.

Tabel 2 Data Indikator di Kabupaten Cilacap

\begin{tabular}{|c|c|c|c|}
\hline Tahun & Kesehatan & Pendidikan & Ekonomi \\
\hline 2010 & 0,8069 & 0.502 & 0,6524 \\
\hline 2011 & 0,8085 & 0.507 & 0,6625 \\
\hline 2012 & 0,81 & 0.525 & 0,6683 \\
\hline 2013 & 0,8115 & 0.547 & 0,6717 \\
\hline 2014 & 0,8123 & 0.557 & 0,6724 \\
\hline 2015 & 0,8154 & 0.560 & 0,6810 \\
\hline 2016 & 0,8171 & 0.571 & 0,6915 \\
\hline
\end{tabular}

Kemudian dilakukan perhitungan IPM di Kabupaten Cilacap. Berikut perhitungan IPM:

a. Tahun 2010

$I P M=\sqrt[3]{0,8069 \times 0,502 \times 0,6524}$

$$
=\sqrt[3]{0,2643}=64,17
$$

b. Tahun 2011

$$
\begin{aligned}
I P M & =\sqrt[3]{0,8085 \times 0,507 \times 0,6625} \\
& =\sqrt[3]{0,2716}=64,76
\end{aligned}
$$

c. Tahun 2012

$$
\begin{aligned}
I P M & =\sqrt[3]{0,81 \times 0,525 \times 0,6683} \\
& =\sqrt[3]{0,2842}=65,75
\end{aligned}
$$


d. Tahun 2013

$$
\begin{aligned}
I P M & =\sqrt[3]{0,8115 \times 0,547 \times 0,6717} \\
& =\sqrt[3]{0,2982}=66,81
\end{aligned}
$$

e. Tahun 2014

$$
\begin{aligned}
I P M & =\sqrt[3]{0,8123 \times 0,557 \times 0,6724} \\
& =\sqrt[3]{0,3042}=67,26
\end{aligned}
$$

f. Tahun 2015

$$
\begin{aligned}
I P M & =\sqrt[3]{0,8154 \times 0,560 \times 0,681} \\
& =\sqrt[3]{0,3110}=67,75
\end{aligned}
$$

g. Tahun 2016

$$
\begin{aligned}
I P M & =\sqrt[3]{0,8171 \times 0,571 \times 0,6915} \\
& =\sqrt[3]{0,3226}=68,59
\end{aligned}
$$

Hasil perhitungan diatas ditunjukkan di Tabel 3.

Tabel 3 Hasil perhitungan IPM Kabupaten Cilacap

\begin{tabular}{|c|c|}
\hline Tahun & IPM \\
\hline 2010 & 65,17 \\
\hline 2011 & 64,76 \\
\hline 2012 & 65,75 \\
\hline 2013 & 66,81 \\
\hline 2014 & 67,26 \\
\hline 2015 & 67,75 \\
\hline 2016 & 68,59 \\
\hline
\end{tabular}

Berdasarkan Tabel 2, dihitung nilai peramalan dan persentase rata-rata kesalahan ramalan dari indikator kesehatan di Kabupaten Cilacap dengan $\alpha=0,2$.

1. Melihat Pola Data

Untuk melihat pola data nilai indikator yang diramalkan dari data time series, dilakukan dengan melihat grafik. Di dalam diagram itu waktu atau periode $(\mathrm{X})$ sebagai absis dan data indikator yang dijadikan sampel $(Y)$ sebagai ordinat. Pemilihan metode Exponential Smoothing yang sesuai berdasarkan pola yang didapat dari data Time Series berdasarkan pola data pada Gambar 2.

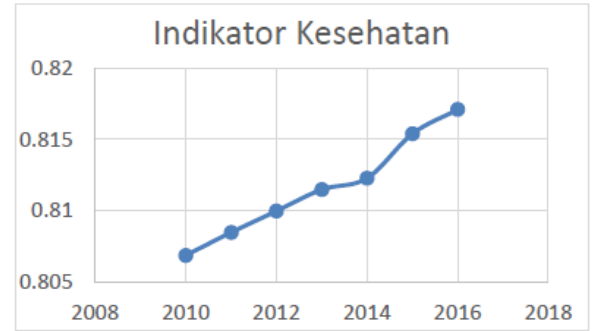
Gambar 2 Grafik Indikator Kesehatan Kabupaten
Cilacap
Dari grafik diatas dapat dilihat bahwa data sampel yang digunakan bersifat trend linier, sehingga peramalan menggunakan double exponential smoothing.

2. Perhitungan Ramalan

Perhitungan peramalan menggunakan double exponential smoothing dari data sampel dengan $\alpha=0,2$ adalah sebagai berikut:

a. Data Sampel 1

$\mathrm{A} 1=0,8069$

$S^{\prime} 1=0,8069$

$S^{\prime \prime} 1=0,8069$

a1 $=0,8069$

$\mathrm{b} 1=0$

$\mathrm{F} 1=0$

b. Data Sampel 2

A2 $=0,8085$

$S^{\prime} 2=(0,2 \times 0,8085)+((1-0,2) \times 0,8069)=0,8072$

$S^{\prime \prime} 2=(0,2 \times 0,8072)+((1-0,2) \times 0,8069)=0,8070$

a2 $=(2 \times 0,8072)-0,8070=0,8075$

$\mathrm{b} 2=(0,2: 0,8) \times(0,8072-0,8070)=0,000064$

$\mathrm{F} 2=0,8069+(0 \times 1)=0,8069$

c. Data Sampel 3

A3 $=0,8100$

$S^{\prime} 3=(0,2 \times 0,81)+((1-0,2) \times 0,8072)=0,8078$

$S^{\prime \prime} 3=(0,2 \times 0,8078)+((1-0,2) \times 0,8070)=0,8071$

a3 $=(2 \times 0,8078)-0,8071=0,8084$

b3 $=(0,2: 0,8) \times(0,8078-0,8071)=0,000162$

F3 $=0,8075+(0,000064 \times 1)=0,80754$

d. Data Sampel 4

A4 $=0,8115$

$S^{\prime} 4=(0,2 \times 0,8115)+((1-0,2) \times 0,8078)=0,8085$

$S^{\prime \prime} 4=(0,2 \times 0,8085)+((1-0,2) \times 0,8071)=0,8074$

$\mathrm{a} 4=(2 \times 0,8085)-0,8074=0,8096$

b4 $=(0,2: 0,8) \times(0,8085-0,8074)=0,000279$

$F 4=0,8084+(0,000162 \times 1)=0,80859$

\section{e. Data Sampel 5}

A5 $=0,8123$

$S^{\prime} 5=(0,2 \times 0,8123)+((1-0,2) \times 0,8085)=0,8093$

$S^{\prime \prime} 5=(0,2 \times 0,8093)+((1-0,2) \times 0,8074)=0,8078$

a5 $=(2 \times 0,8093)-0,8078=0,8108$

b5 $=(0,2: 0,8) \times(0,8093-0,8078)=0,000374$

$F 5=0,8096+(0,000279 \times 1)=0,80992$

f. Data Sampel 6

A6 $=0,8154$

$S^{\prime} 6=(0,2 \times 0,8154)+((1-0,2) \times 0,8093)=0,8105$

$S^{\prime \prime} 6=(0,2 \times 0,8105)+((1-0,2) \times 0,8078)=0,8083$

$\mathrm{a} 6=(2 \times 0,8105)-0,8083=0,8127$

$\mathrm{b} 6=(0,2: 0,8) \times(0,8105-0,8083)=0,000544$

$\mathrm{F} 6=0,8127+(0,000374 \times 1)=0,81115$ 
g. Data Sampel 7

A7 $=0,8171$

$S^{\prime} 7=(0,2 \times 0,8171)+((1-0,2) \times 0,8105)=0,8118$

$S^{\prime \prime} 7=(0,2 \times 0,8118)+((1-0,2) \times 0,8083)=0,8090$

a7 $=(2 \times 0,8118)-0,8090=0,8146$

b7 $=(0,2: 0,8) \times(0,8118-0,8090)=0,000699$

$\mathrm{F} 7=0,8127+(0,000544 \times 1)=0,81322$

Dari perhitungan diatas maka hasil peramalan dengan $\alpha: 0,2$ ditunjukkan pada Tabel 4 .

Tabel 4 Hasil Perhitungan Peramalan $\alpha: \mathbf{0 , 2}$.

\begin{tabular}{|l|l|l|}
\hline Tahun & Data & Hasil Ramalan \\
\hline 2010 & 80.692 & 0 \\
\hline 2011 & 80.846 & 80.692 \\
\hline 2012 & 81.00 & 80.7538 \\
\hline 2013 & 81.154 & 80.8585 \\
\hline 2014 & 81.231 & 80.9926 \\
\hline 2015 & 81.538 & 81.1157 \\
\hline 2016 & 81.708 & 81.3221 \\
\hline 2017 & 0 & 81.5306 \\
\hline
\end{tabular}

3. Menghitung Kesalahan Ramalan

Hasil perhitungan kesalahan ramalan indikator kesehatan dengan $\alpha: 0,2$ dapat dilihat pada Tabel 5.

Tabel 5 Hasil Perhitungan Kesalahan Peramalan Indikator Kesehatan $\alpha: 0,2$.

\begin{tabular}{|c|c|c|c|c|c|c|}
\hline Tahun & Data & $\begin{array}{c}\text { Hasil } \\
\text { Ramal } \\
\text { an }\end{array}$ & $\begin{array}{c}\text { Erro } \\
r\end{array}$ & $\begin{array}{c}\text { Erro } \\
r^{2}\end{array}$ & $\mathrm{PE}$ & |PE| \\
\hline 2010 & $\begin{array}{c}0,806 \\
9\end{array}$ & 0 & 0 & 0 & 0 & 0 \\
\hline 2011 & $\begin{array}{c}0,808 \\
5\end{array}$ & $\begin{array}{c}0,8069 \\
0\end{array}$ & $\begin{array}{c}0.00 \\
160\end{array}$ & $\begin{array}{l}0.00 \\
000 \\
256\end{array}$ & $\begin{array}{c}0.19 \\
789 \\
734 \\
1 \\
\end{array}$ & $\begin{array}{c}0.19 \\
789 \\
734 \\
1\end{array}$ \\
\hline 2012 & $\begin{array}{c}0,810 \\
0\end{array}$ & $\begin{array}{c}0,8075 \\
4\end{array}$ & $\begin{array}{l}0.00 \\
246\end{array}$ & $\begin{array}{l}0.00 \\
000 \\
605\end{array}$ & $\begin{array}{c}0.30 \\
370 \\
370 \\
4 \\
\end{array}$ & $\begin{array}{c}0.30 \\
370 \\
370 \\
4\end{array}$ \\
\hline 2013 & $\begin{array}{c}0,811 \\
5\end{array}$ & $\begin{array}{c}0,8085 \\
9\end{array}$ & $\begin{array}{l}0.00 \\
291\end{array}$ & $\begin{array}{l}0.00 \\
000 \\
848\end{array}$ & $\begin{array}{c}0.35 \\
884 \\
165 \\
1\end{array}$ & $\begin{array}{c}0.35 \\
884 \\
165 \\
1\end{array}$ \\
\hline 2014 & $\begin{array}{c}0,812 \\
3\end{array}$ & $\begin{array}{c}0,8099 \\
2\end{array}$ & $\begin{array}{l}0.00 \\
238\end{array}$ & $\begin{array}{l}0.00 \\
000 \\
569\end{array}$ & $\begin{array}{c}0.29 \\
358 \\
611 \\
4 \\
\end{array}$ & $\begin{array}{c}0.29 \\
358 \\
611 \\
4\end{array}$ \\
\hline 2015 & $\begin{array}{c}0,815 \\
4\end{array}$ & $\begin{array}{c}0,8111 \\
5\end{array}$ & $\begin{array}{l}0.00 \\
425\end{array}$ & $\begin{array}{l}0.00 \\
001 \\
808\end{array}$ & $\begin{array}{c}0.52 \\
146 \\
185 \\
9 \\
\end{array}$ & $\begin{array}{c}0.52 \\
146 \\
185 \\
9 \\
\end{array}$ \\
\hline 2016 & $\begin{array}{c}0,817 \\
1\end{array}$ & $\begin{array}{c}0,8132 \\
2\end{array}$ & $\begin{array}{l}0.00 \\
388\end{array}$ & $\begin{array}{l}0.00 \\
001 \\
503\end{array}$ & $\begin{array}{c}0.47 \\
447 \\
411 \\
6\end{array}$ & $\begin{array}{c}0.47 \\
447 \\
411 \\
6\end{array}$ \\
\hline \multicolumn{3}{|c|}{ Jumlah } & $\begin{array}{c}0.01 \\
748 \\
57\end{array}$ & $\begin{array}{c}0.00 \\
005 \\
59\end{array}$ & $\begin{array}{c}2.14 \\
996 \\
48\end{array}$ & $\begin{array}{c}2.14 \\
996 \\
48\end{array}$ \\
\hline
\end{tabular}

a. Mean Square Error (MSE)

$$
M S E=\frac{4,622349}{7}=0,660336
$$

b. Mean Absolute Percentage Error (MAPE)

$M A P E=\frac{2,1499648}{7}=0,307138$
Jadi rata - rata kesalahan (Error) absolut antara hasil peramalan dengan nilai sebenarnya adalah 0,660336, dan persentase rata-rata kesalahan ramalan adalah 0,307138 .

4. Menghitung Ramalan Indeks Pembangunan Manusia Ramalan

Proses perhitungan ini menggunakan data IPM Kabupaten Cilacap. Langk untuk perhitungan peramalan sama dengan langkah perhitungan peramalan indikator penyusun IPM. Untuk melihat pola dari data IPM, dapat dilihat di Gambar 3.

\section{IPM Kabupaten Cilacap}

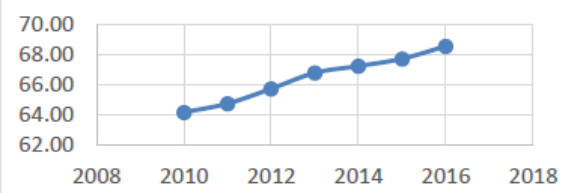

\section{Gambar 3 Grafik IPM Kabupaten Cilacap}

Dari grafik diatas dapat dilihat bahwa data sampel yang digunakan bersifat trend linier, maka peramalan menggunakan double exponential. Selanjutnya dilakukan perhitungan peramalan IPM dengan alpha 0,2, berikut perhitungan peramalan IPM Kabupaten Cilacap:

\section{Data Sampel 1}

$A 1=64,17$

$S^{\prime} 1=64,17$

S"1 $=64,17$

a1 $=64,17$

b1 $=0$

$\mathrm{F} 1=0$

\section{Data Sampel 2}

$\mathrm{A} 2=64,76$

$S^{\prime} 2=(0,2 \times 64,76)+((1-0,2) \times 64,17)=64,289$

$S^{\prime \prime} 2=(0,2 \times 64,289)+((1-0,2) \times 64,17)=64,1955$

a2 $=(2 \times 64,289)-64,1955=64,3829$

$\mathrm{b} 2=(0,2: 0,8) \times(64,289-64,1955)=0,023426$

$\mathrm{F} 2=64,17+(0 \times 1)=64,17203$

\section{Data Sampel 3}

A3 $=65,75$

$S^{\prime} 3=(0,2 \times 65,75)+((1-0,2) \times 64,289)=64,581$

$S^{\prime \prime} 3=(0,2 \times 64,581)+((1-0,2) \times 64,1955)=64,2725$

a3 $=(2 \times 64,581)-64,2725=64,8887$

b3 $=(0,2: 0,8) \times(64,581-64,2725)=0,077030$

$\mathrm{F} 3=64,3829+(0,023426 \times 1)=64,40629$

\section{Data Sampel 4}

A4 $=66,81$

$S^{\prime} 4=(0,2 \times 66,81)+((1-0,2) \times 64,581)=65,026$

$S^{\prime \prime} 4=(0,2 \times 65,026)+((1-0,2) \times 64,2725)=64,4231$

$\mathrm{a} 4=(2 \times 65,026)-64,4231=65,6283$

b4 $=(0,2: 0,8) \times(65,026-64,4231)=0,150649$

$F 4=64,8887+(0,077030 \times 1)=64,96576$ 


\section{Data Sampel 5}

$\mathrm{A} 5=67,26$

$S^{\prime} 5=(0,2 \times 67,26)+((1-0,2) \times 65,026)=65,472$

$S^{\prime \prime} 5=(0,2 \times 65,472)+((1-0,2) \times 64,4231)=64,6329$

a5 $=(2 \times 65,472)-64,6329=66,3108$

b5 $=(0,2: 0,8) \times(65,472-64,6329)=0,209743$

$F 5=65,6283+(0,150649 \times 1)=65,77898$

\section{Data Sampel 6}

$A 6=67,75$

$S^{\prime} 6=(0,2 \times 67,75)+((1-0,2) \times 65,472)=65,927$

$S^{\prime \prime} 6=(0,2 \times 65,927)+((1-0,2) \times 64,6329)=64,8918$

$\mathrm{a} 6=(2 \times 65,927)-64,8918=66,9628$

b6 $=(0,2: 0,8) \times(65,927-64,8918)=0,258874$

$F 6=66,3108+(0,209743 \times 1)=66,52057$

\section{Data Sampel 7}

$\mathrm{A} 7=68,59$

$S^{\prime} 7=(0,2 \times 68,59)+((1-0,2) \times 65,927)=66,459$

$S^{\prime \prime} 7=(0,2 \times 66,459)+((1-0,2) \times 64,8918)=65,2052$

a7 $=(2 \times 66,459)-65,2052=67,7127$

b7 $=(0,2: 0,8) \times(66,459-65,2052)=0,313443$

$F 7=66,9628+(0,258874 \times 1)=67,22163$

Hasil ramalan IPM dengan $\alpha: 0,2$ dapat dilihat pada Tabel 6.

Tabel 6 Hasil Perhitungan Peramalan IPM

Kabupaten Cilacap $\alpha: \mathbf{0 , 2}$.

\begin{tabular}{|l|l|l|}
\hline Tahun & Data & Hasil Ramalan \\
\hline 2010 & 64.17 & 0 \\
\hline 2011 & 64.76 & 64.17203 \\
\hline 2012 & 65.75 & 64.40629 \\
\hline 2013 & 66.81 & 64.96576 \\
\hline 2014 & 67.26 & 95.77898 \\
\hline 2015 & 67.75 & 66.52057 \\
\hline 2016 & 68.59 & 67.22163 \\
\hline
\end{tabular}

5. Menghitung Kesalahan Ramalan Indeks Pembangunan Manusia

Hasil perhitungan kesalahan ramalan IPM dengan $\alpha: 0,2$ dapat dilihat pada Tabel 7 .

Tabel 7 Hasil Perhitungan Kesalahan Peramalan IPM $\alpha: \mathbf{0 , 2}$.

\begin{tabular}{|c|c|c|c|c|c|c|}
\hline $\begin{array}{c}\text { Tahu } \\
\mathrm{n}\end{array}$ & Data & $\begin{array}{c}\text { Hasil } \\
\text { Rama } \\
\text { lan }\end{array}$ & $\begin{array}{c}\text { Erro } \\
r\end{array}$ & $\begin{array}{c}\text { Erro } \\
r^{2}\end{array}$ & $\mathrm{PE}$ & $|\mathrm{PE}|$ \\
\hline 2010 & 64,17 & 0 & 0 & 0 & 0 & 0 \\
\hline 2011 & 64,76 & $\begin{array}{c}64,17 \\
203\end{array}$ & $\begin{array}{l}0,58 \\
565\end{array}$ & $\begin{array}{c}0,34 \\
298\end{array}$ & $\begin{array}{l}0.90 \\
437\end{array}$ & $\begin{array}{l}0.90 \\
437\end{array}$ \\
\hline 2012 & 65,75 & $\begin{array}{c}64,40 \\
629\end{array}$ & $\begin{array}{l}1,34 \\
010\end{array}$ & $\begin{array}{l}1,79 \\
587\end{array}$ & $\begin{array}{l}2,03 \\
829\end{array}$ & $\begin{array}{l}2,03 \\
829\end{array}$ \\
\hline 2013 & 66,81 & $\begin{array}{c}64,96 \\
576\end{array}$ & $\begin{array}{l}1,84 \\
049 \\
\end{array}$ & $\begin{array}{c}3,38 \\
739 \\
\end{array}$ & $\begin{array}{l}2,75 \\
496\end{array}$ & $\begin{array}{l}2,75 \\
496\end{array}$ \\
\hline 2014 & 67,26 & $\begin{array}{c}65,77 \\
898\end{array}$ & $\begin{array}{l}1,47 \\
734\end{array}$ & $\begin{array}{l}2,18 \\
253\end{array}$ & $\begin{array}{l}2,19 \\
658\end{array}$ & $\begin{array}{l}2,19 \\
658\end{array}$ \\
\hline 2015 & 67,75 & $\begin{array}{c}66,52 \\
057 \\
\end{array}$ & $\begin{array}{l}1,22 \\
828 \\
\end{array}$ & $\begin{array}{l}1,50 \\
868 \\
\end{array}$ & $\begin{array}{l}1,81 \\
300 \\
\end{array}$ & $\begin{array}{l}1,81 \\
300 \\
\end{array}$ \\
\hline 2016 & 68,59 & $\begin{array}{c}67,22 \\
163\end{array}$ & $\begin{array}{l}1,36 \\
422\end{array}$ & $\begin{array}{l}1,86 \\
110\end{array}$ & $\begin{array}{l}1,98 \\
907\end{array}$ & $\begin{array}{l}1,98 \\
907\end{array}$ \\
\hline \multicolumn{3}{|c|}{ Jumlah } & $\begin{array}{l}7,83 \\
608\end{array}$ & $\begin{array}{l}11,0 \\
786\end{array}$ & $\begin{array}{l}11,6 \\
963\end{array}$ & $\begin{array}{l}11,6 \\
963\end{array}$ \\
\hline
\end{tabular}

a. Mean Square Error (MSE)

$$
\begin{aligned}
& M S E=\frac{\sum\left|x_{t}-S_{t}\right|^{2}}{n} \\
& M S E=\frac{61,404179}{7}=8,772026
\end{aligned}
$$

b. Mean Absolute Percentage Error (MAPE)

$$
P E=\frac{\sum\left|x_{t}-s_{t}\right|}{x_{t}} \times 100
$$

$$
M A P E=\frac{\sum|P E|}{n}=\frac{7,83608}{7}=1,1194
$$

Jadi rata - rata kesalahan absolut IPM peramalan adalah 1,1194, dan persentase ratarata kesalahan IPM ramalan adalah 8,772026.

\subsection{Use Case Diagram}

Use case diagram [16] dari aplikasi Peramalan Tingkat Indeks Pembangunan Manusia Berbasis Sistem Informasi Geografis Di Provinsi Jawa Tengah diperlihatkan pada Gambar 4.

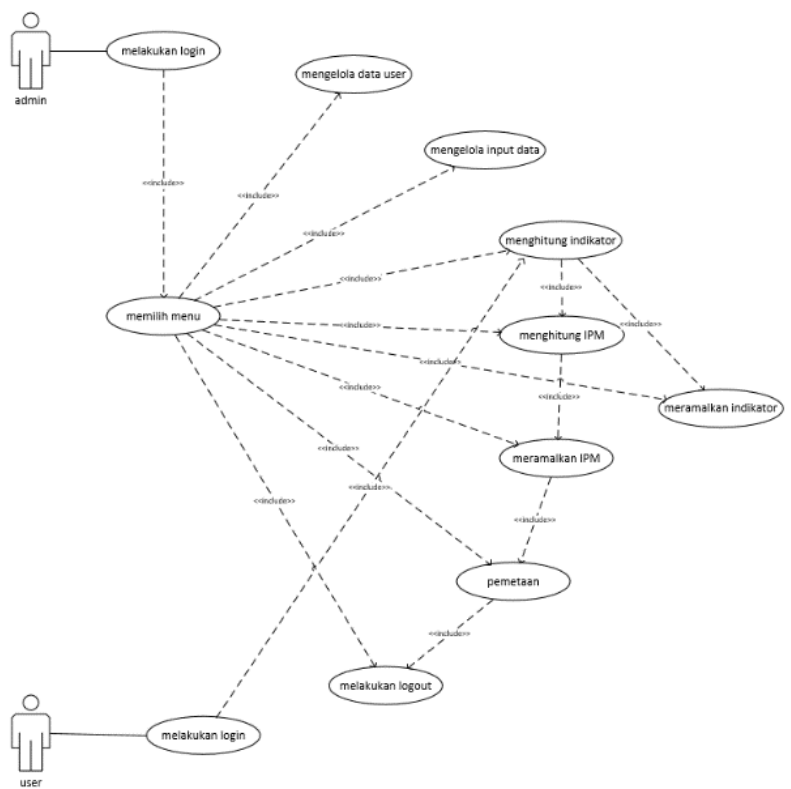

Gambar 4 Use Case Diagram Aplikasi Peramalan Tingkat Indeks Pembangunan Manusia Jawa Tengah

\subsection{Class Diagram \\ Class diagram [16] dari sistem yang} dibangun ditunjukkan pada Gambar 5. 


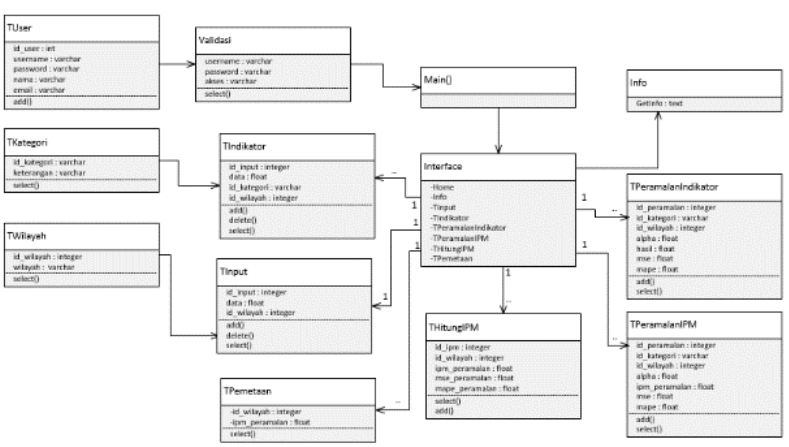

Gambar 5 Class Diagram Aplikasi Peramalan Tingkat Indeks Pembangunan Manusia

\subsection{Pengujian}

\section{Blackbox}

Blackbox adalah uji coba yang dilakukan pada interface software, dan digunakan untuk mendemonstrasikan fungsi software, apakah input diterima dengan benar, dan output yang dihasilkan benar.

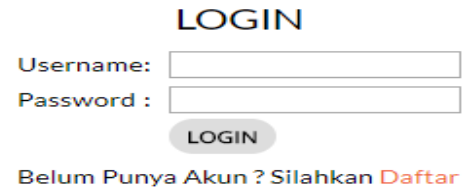

\section{Gambar 6 Form Login}

Ketika sistem akan dijalankan maka pertama kali adalah melakukan login. Hanya pengguna yang memiliki username dan password yang dapat menggunakan aplikasi ini. Apabila username atau password masih kosong maka akan muncul message box seperti pada gambar 6 Ketika pengguna salah mengisi username atau password maka message box juga akan muncul seperti pada Gambar 7.

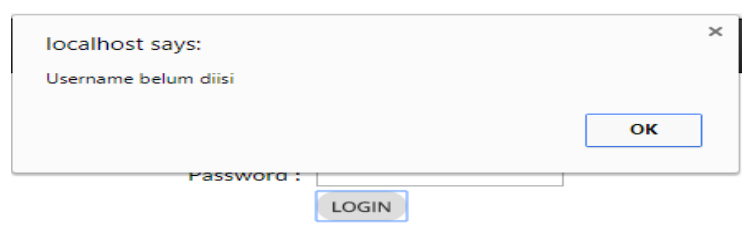

Gambar 7 Message Box Muncul Jika Username atau Password Kosong

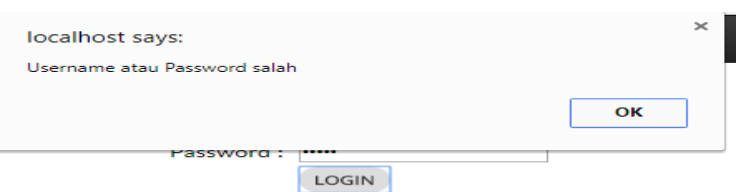

Gambar 8 Message Box Muncul Jika Username atau Password Salah

\section{Validasi}

Untuk pengujian validitas dilakukan dengan membandingkan Mean Squared Error (MSE) dan Mean Absolute Percent Error (MAPE) secara manual dengan nilai alpha yang berbeda-beda. Untuk perhitungan ini data yang digunakan adalah data IPM Kabupaten Cilacap dari tahun 2010-2016.

Tabel 8 Data IPM Kabupaten Cilacap

\begin{tabular}{|l|l|}
\hline Tahun & Data \\
\hline 2010 & 64.17 \\
\hline 2011 & 64.76 \\
\hline 2012 & 65.75 \\
\hline 2013 & 66.81 \\
\hline 2014 & 67.26 \\
\hline 2015 & 67.75 \\
\hline 2016 & 68.59 \\
\hline
\end{tabular}

Hasil perhitungan manual peramalan IPM dan kesalahan ramalan dengan data pada Tabel 6 ditunjukkan pada Tabel 9 dengan nilai $\alpha=0,2$ hingga 0,9 .

Tabel 9 Hasil Peramalan Secara Manual Dan Kesalahan Peramalan IPM

\begin{tabular}{|c|c|c|c|c|c|c|c|c|c|}
\hline \multirow{2}{*}{$\underset{n}{\text { Tahu }}$} & \multicolumn{9}{|c|}{ Hasil Ramalan } \\
\hline & $\begin{array}{l}a= \\
0,1\end{array}$ & $\begin{array}{l}a= \\
0,2\end{array}$ & $\begin{array}{l}a== \\
0,3\end{array}$ & $\begin{array}{l}\alpha= \\
0,4\end{array}$ & $\begin{array}{l}a= \\
0,5\end{array}$ & $\begin{array}{l}a= \\
0,6\end{array}$ & $\begin{array}{l}a= \\
0,7\end{array}$ & $\begin{array}{l}a= \\
0,8\end{array}$ & $\begin{array}{l}\alpha= \\
0,9\end{array}$ \\
\hline 2010 & 0 & 0 & 0 & 0 & 0 & 0 & 0 & 0 & 0 \\
\hline 2011 & $\begin{array}{l}64, \\
17\end{array}$ & $\begin{array}{c}64, \\
17\end{array}$ & $\begin{array}{l}64, \\
17\end{array}$ & $\begin{array}{l}64, \\
17\end{array}$ & $\begin{array}{l}64, \\
17\end{array}$ & $\begin{array}{l}64, \\
17\end{array}$ & $\begin{array}{c}64, \\
17\end{array}$ & $\begin{array}{l}64, \\
17\end{array}$ & $\begin{array}{l}64, \\
17\end{array}$ \\
\hline 2012 & $\begin{array}{c}64 \\
28 \\
8\end{array}$ & $\begin{array}{l}64 \\
40 \\
60\end{array}$ & $\begin{array}{c}64 \\
52 \\
4\end{array}$ & $\begin{array}{l}64, \\
64 \\
20\end{array}$ & $\begin{array}{l}64, \\
76\end{array}$ & $\begin{array}{c}64 \\
87 \\
8\end{array}$ & $\begin{array}{l}64 \\
99 \\
60\end{array}$ & $\begin{array}{l}65, \\
11 \\
40\end{array}$ & $\begin{array}{l}65 \\
23 \\
20\end{array}$ \\
\hline 2013 & $\begin{array}{c}64 \\
58 \\
6\end{array}$ & $\begin{array}{l}64, \\
96 \\
72\end{array}$ & $\begin{array}{l}65, \\
31 \\
27\end{array}$ & $\begin{array}{l}65, \\
62 \\
28\end{array}$ & $\begin{array}{l}65, \\
89 \\
75\end{array}$ & $\begin{array}{l}66, \\
13 \\
68\end{array}$ & $\begin{array}{l}66, \\
34 \\
07\end{array}$ & $\begin{array}{l}66, \\
50 \\
92\end{array}$ & $\begin{array}{l}66, \\
64 \\
23\end{array}$ \\
\hline 2014 & $\begin{array}{l}65 \\
05 \\
16\end{array}$ & $\begin{array}{c}65 \\
78 \\
17\end{array}$ & $\begin{array}{l}66, \\
37 \\
45\end{array}$ & $\begin{array}{l}66, \\
84 \\
42\end{array}$ & $\begin{array}{l}67 \\
20 \\
50\end{array}$ & $\begin{array}{c}67 \\
47 \\
1\end{array}$ & $\begin{array}{l}67 \\
65 \\
63\end{array}$ & $\begin{array}{l}67 \\
77 \\
51\end{array}$ & $\begin{array}{l}67, \\
84 \\
16\end{array}$ \\
\hline 2015 & $\begin{array}{l}65 \\
53 \\
60\end{array}$ & $\begin{array}{l}66, \\
52 \\
41\end{array}$ & $\begin{array}{l}67 \\
20 \\
40\end{array}$ & $\begin{array}{l}67 \\
63 \\
85\end{array}$ & $\begin{array}{l}67 \\
88 \\
31\end{array}$ & $\begin{array}{l}67 \\
98 \\
65\end{array}$ & $\begin{array}{c}67 \\
99 \\
0\end{array}$ & $\begin{array}{l}67 \\
92 \\
81\end{array}$ & $\begin{array}{l}67 \\
82 \\
80\end{array}$ \\
\hline 2016 & $\begin{array}{l}66, \\
04 \\
36\end{array}$ & $\begin{array}{l}67, \\
22 \\
47\end{array}$ & $\begin{array}{l}67 \\
90 \\
95\end{array}$ & $\begin{array}{l}68 \\
25 \\
58\end{array}$ & $\begin{array}{l}68, \\
38 \\
69\end{array}$ & $\begin{array}{c}68 \\
39 \\
54\end{array}$ & $\begin{array}{l}68 \\
34 \\
83\end{array}$ & $\begin{array}{l}68 \\
29 \\
06\end{array}$ & $\begin{array}{l}68 \\
24 \\
98\end{array}$ \\
\hline MSE & $\begin{array}{c}3,3 \\
84 \\
8\end{array}$ & $\begin{array}{c}1,5 \\
86 \\
1\end{array}$ & $\begin{array}{c}0,8 \\
05 \\
5\end{array}$ & $\begin{array}{c}0,4 \\
68 \\
9\end{array}$ & $\begin{array}{c}0,3 \\
17 \\
6\end{array}$ & $\begin{array}{c}0,2 \\
42 \\
9\end{array}$ & $\begin{array}{c}0,2 \\
01 \\
4\end{array}$ & $\begin{array}{c}0,1 \\
75 \\
7\end{array}$ & $\begin{array}{r}0,1 \\
57 \\
8\end{array}$ \\
\hline $\begin{array}{c}\text { MAP } \\
E\end{array}$ & $\begin{array}{c}2,3 \\
89 \\
5\end{array}$ & $\begin{array}{c}1,6 \\
73 \\
1\end{array}$ & $\begin{array}{c}1,1 \\
61 \\
6\end{array}$ & $\begin{array}{c}0,8 \\
06 \\
2\end{array}$ & $\begin{array}{c}0,6 \\
22 \\
4\end{array}$ & $\begin{array}{c}0,5 \\
98 \\
8\end{array}$ & $\begin{array}{c}0,5 \\
79 \\
4\end{array}$ & $\begin{array}{c}0,5 \\
42 \\
0\end{array}$ & $\begin{array}{c}0,4 \\
89 \\
4\end{array}$ \\
\hline
\end{tabular}

Dari Tabel 7 menunjukkan bahwa dengan nilai $\alpha=0,9$ menghasilkan peramalan tahun berikut nya yaitu : 69,3612 dengan kesalahan MSE terkecil yaitu : 0,1578 dan nilai MAPE yaitu : 0,4894 .

Hasil yang diperoleh dari perhitungan manual atau perhitungan dengan aplikasi peramalan besarnya kesalahan MSE 
merupakan hasil yang terkecil karena paling mendekati 0 dan besarnya MAPE kecil karena besarnya kesalahan kurang dari 10 sehingga hasil peramalan dapat dijadikan dasar untuk mengambil keputusan.

Input data untuk perhitungan peramalan di program dengan menginputkan wilayah dan nilai alpha, terlihat pada Gambar 9 .

Peramalan IPM

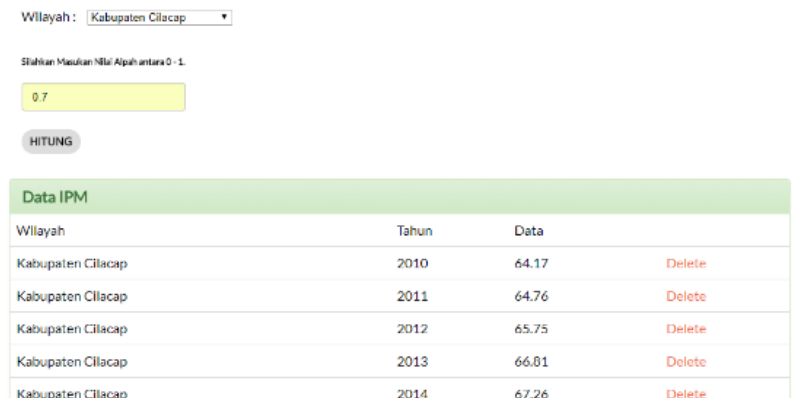

Gambar 9 Form Input Peramalan IPM

Output hasil perhitungan manual dengan hasil perhitungan aplikasi memiliki hasil yang sama seperti ditunjukkan pada Gambar 10.

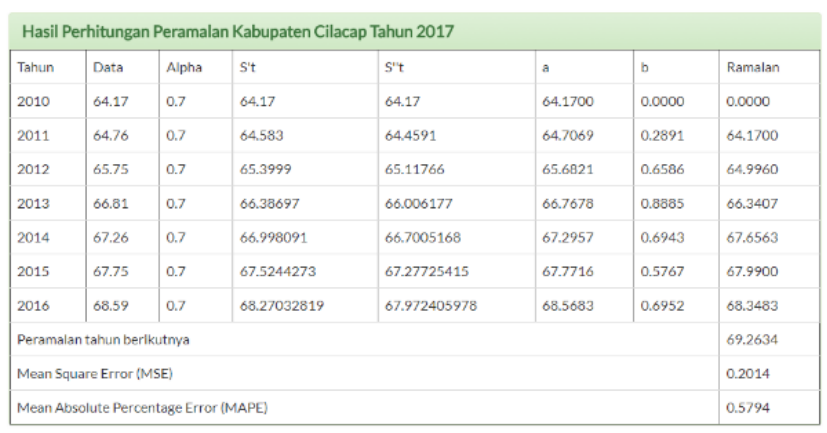

\section{Gambar 10 Hasil Perhitungan Aplikasi}

Hasil peramalan IPM tahun berikutnya pada $\alpha=$ 0,9 menghasilkan nilai peramalan : 69,3612. Hasil tersebut menunjukkan bahwa IPM Kabupaten Cilacap berada pada kelompok wilayah dengan pembangunan manusia "sedang" di Provinsi Jawa Tengah.

\section{Pemetaan}

Dalam pemetaan, data berformat shape file $\left({ }^{*}\right.$.shp) berisi koordinat wilayah daerah kabupaten dan kota di Jawa Tengah, API Key Google Fusion Table dan API Key Google Maps yang digunakan untuk menampilkan peta pada halaman aplikasi.

Untuk menampilkan peta pada halaman aplikasi, peneliti menggunakan JavaScript. Untuk menampilkan polygon wilayah tiap daerah di halaman peta, dilakukan konversi file ${ }^{*}$.shp yang sudah ada ke file ${ }^{*} . \mathrm{kml}$. Hal ini dilakukan karena pada Fusion Table, data yang digunakan adalah ${ }^{*} . \mathrm{kml}$, file tersebut akan di upload ke database Fusion Table.

Selanjutnya dilakukan edit pada rows Fusion Table, dengan penambahan kolom kode, ini dilakukan agar dapat sinkron dengan database MySQL.

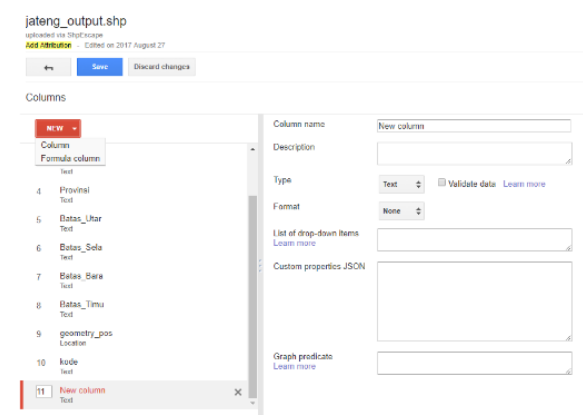

Gambar 11 Halaman edit Column Google Fusion Table

Setelah dilakukan penambahan pada Google Fusion Table, dilakukan juga penambahan kolom id_wilayah pada database $M y S Q L$, kolom berisi sama dengan kolom kode pada Google Fusion Table agar data pada $M y S Q L$ dapat di tampilkan pada peta. Penulisan program menggunakan javascript dan PHP dan API Key Google Fusion Table agar polygon wilayah daerah kabupaten dan kota dapat tampil. Dilakukan juga range data agar dapat menampilkan warna yang di range pada wilayah daerah kabupaten dan kota, seperti terlihat pada Gambar 12.

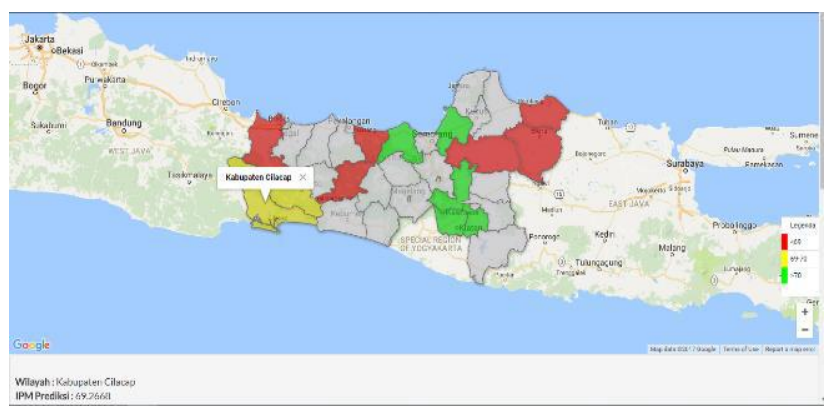

Gambar 12 Halaman Hasil Pemetaan

\section{PENUTUP}

\subsection{Kesimpulan}

Berdasarkan penelitian yang telah dilakukan maka dapat disimpulkan sebagai berikut: 
1. Untuk mencari hasil peramalan indikator IPM maupun peramalan IPM yang akurat dilakukan dengan mencari nilai alpha terbaik dengan melihat MSE dan MAPE yang terkecil dengan membandingkan nilai alpha dari hasil ramalan. Hasil peramalan IPM Kabupaten Cilacap yang diperoleh yaitu 69,3612 dengan nilai alpha 0,9, hasil tersebut menunujukkan bahwa IPM Kabupaten Cilacap berada pada kelompok wilayah dengan IPM "sedang".

2. Hasil dari perhitungan manual maupun perhitungan aplikasi dengan metode double exponential smoothing menghasilkan nilai MSE sebesar 0,1578 dan nilai MAPE sebesar 0,4894. Nilai MAPE dan MSE yang dihasilkan termasuk nilai MSE dan MAPE yang kecil karena nilai MSE mendekati 0 dan MAPE kurang dari 10 , sehingga metode ini cocok digunakan untuk peramalan IPM.

3. Aplikasi yang dibuat dengan bahasa pemrograman PHP dan JavaScript menghasilkan informasi peramalan indikator IPM dan peramalan IPM. Hasil peramalan IPM dapat di tampilkan dalam bentuk peta per masing-masing kabupaten dan kota di Jawa Tengah dengan menggunakan fasilitas Google Fusion Table dan Google Maps API.

\subsection{Saran}

1. Agar hasil peramalan lebih akurat, aplikasi sebaiknya menghitung peramalan dengan menggunakan metode lain seperti ARIMA, Triple Exponential atau Moving Average

2. Dalam menentukan nilai alpha terbaik dapat dilakukan secara otomatis dalam pengembangan aplikasi.

3. Pemetaan dapat dikembangkan lagi dengan memilah dan memberi tanda di wilayah yang telah di lakukan peramalan, dengan melakukan range data hasil IPM Peramalan secara manual.

\section{DAFTAR PUSTAKA}

[1] S. A. Rezwari, 2015, Simulasi Peramalan Tingkat Indeks Pembangunan Manusia Di Provinsi Jawa Tengah Dengan Metode Exponential Smoothing Menggunakan Microsoft Visual Basic 6.0, http://lib.unnes.ac.id/21755/, diakses tgl 21 Juni 2017.

[2] N. S. Maedja, 2014, Peramalan Produksi Daging Berbasis Sistem Informasi Geografis Di Provinsi Gorontalo, http://eprints.ung.ac.id/4579/, diakses tgl 18 Juni 2017.

[3] E. N. Putri, 2016, Prediksi Harga Sembako Menggunakan Metode Duoble Exponential Smoothing (DES) Di Kota Surakarta, Jurnal STMIK Sinar Nusantara

[4] Z. Peng, 2015, Research on Industrialization of Electric Vehicles with its Demand Forecast Using Exponential Smoothing Method, http://www.jiem.org /index.php/jiem/article/vie

[5] Badan Pusat Statistik, 2015, Booklet IPM Metode Baru, Badan Pusat Statistik, Jakarta.

[6] N. Djalal and H. Usman, 2004, Teknik Pengambilan Keputusan, Grasindo, Jakarta.

[7] D. Siagian and S. Usman, 2000, Metode Statistika Untuk Bisnis Dan Ekonomi, Gramedia Pustaka Utama, Jakarta.

[8] H. I. Gitosudarmo and M. Najmudin, 2000, Teknik Proyeksi Bisnis, BPFE-UGM, Yogyakarta.

[9] S. Makridaksi, S. C. Wheelwright and V. E. McGreen, 1999, Metode Dan Aplikasi Peramalan, Jilid I, Bina Rupa Aksara, Jakarta.

[10] Supono and V. Putratama, 2016, Pemrograman Web dengan Menggunakan PHP dan Freamwork Codeigniter, Deepublish, Yogyakarta

[11] B. H. Sirenden and E. Laekha, 2012, Buat Sendiri Aplikasi Petamu Menggunakan Codelgniter Dan Google Maps API, Andi Publisher, Yogyakarta.

[12] Departemen Kehutanan, 2017, http://appgis.dephut.go.id/appgis/kml.aspx, diakses tgl 9 Juni 2017.

[13] M. R. Nahado, 2015, Bumbu Bumbu Membuat Website: Cara Membuat Website Cantik dan Mudah.

[14] H. Gonzalez, Halevy Alon, C. S. Jensen, A. Langen, J. Madhavan, R. Shapley and W. Shen, 2010, Google Fusion Tables: Data Management, Integration and Collaboration in the Cloud.

[15] E. Herjanto, 2008, Manajemen Operasi (Edisi 3), Grasindo, Jakarta.

[16] M. Salahuddin and R. A. S, 2013, Rekayasa Perangkat Lunak Terstruktur dan Berorientasi Objek, Informatika Bandung, Bandung. 